\title{
UTILIZAÇÃO DO CUSTO TOTAL DE USO E PROPRIEDADE NA DECISÃO DE IMPLANTAÇÃO DO SISTEMA NFE-S
}

\author{
Reni Cesar Gotta ${ }^{1}$
}

\section{RESUMO}

A evolução no uso da TI nas mais diversas áreas da sociedade seja na iniciativa privada ou pública tem ganhado contorno de indispensáveis, principalmente no que tange os processos internos que buscam incessantemente a modernização de seus procedimentos burocratizados e enfadados. Nesse contexto a inovação tecnológica é um aliado da administração publica municipal que necessita de sistemas modernos e robustos, nesse pressuposto vale um destaque para os sistemas disponibilizados via web. A Internet destaca-se entre as tecnologias que provoca mudanças no modo de funcionamento do setor público. Como o canal de comunicação mundial, ela começa a provocar mudanças na interação do governo com a sociedade, apresentando-se como uma ferramenta que pode tornar o governo mais eficiente por oferecer redução de custos e acesso rápido, e possibilitar a desburocratização da relação dos órgãos públicos com o cidadão. O referido artigo objetivou essa relação da modernidade tecnológica utilizadas pelo setor público brasileiro com o cidadão, a partir disso foi amplamente explanado no referencial teórico do objeto de estudo desse artigo. Ainda trouxe a discussão da utilização do sistema da nota fiscal eletrônica de serviços por prefeituras de todo país como uma ferramenta de combate a sonegação e evasão fiscal, assim como, esta esse mercado atualmente, para tanto, utilizou-se a técnica de se calcular o custo total de propriedade total cost of ownership (TCO) no intuito principal de buscar a relação custo $\mathrm{x}$ beneficio num ente publico, que possibilitou ainda a realização de um estudo comparativo de custos no uso do sistema da nota fiscal eletrônica de serviços via software proprietário ou através de uma nova modalidade de contratação via software público. Nesse contexto observou-se que atualmente as prefeituras têm um novo formato de aquisição de tecnologia e que através desse hoje é possível contratar softwares robustos que atendam a totalidade das demandas do município, objetivando economia aos cofres públicos do município e a prestação de serviços com alta qualidade aos cidadãos.

Palavras-chave: Tecnologia da Informação. Software. Nota Fiscal Eletrônica de Serviços.

\section{Introdução}

Atualmente se confirma uma evolução tecnológica que vem apresentando profundas transformações na sociedade recente. Esse processo tecnológico das organizações, públicas ou privadas, embora às vezes feito de uma maneira empírica, gera um volume de informações admirável. Por isso torna-se necessário então, que exista uma sistematização para que os benefícios desse processo possam ser utilizados como uma ferramenta de gestão. Dados sem contextualização não geram informação nem conhecimento. Desta forma, processos, sistemas, pessoas, equipamentos, enfim, todo recurso disponível e que participe de alguma maneira da

\footnotetext{
${ }^{1}$ Bacharel em Ciências Contábeis, Professor de Contabilidade, Pós-Graduado Formação Pedagógica Faculdades Celer, Mestrando - PUCRS em Economia do Desenvolvimento. E-mail: prof.cesargotta@hotmail.com 
aquisição da informação deve ser gerenciado. A variedade de opções tecnológicas é seguramente um dos grandes dilemas dos gestores pela utilização dessa tecnologia, pois devem decidir qual opção tecnológica melhor se adapta a cada situação na organização.

Eleger e implementar de forma adequada as melhores tecnologias dentro do contexto organizacional, para apoiar esta em suas estratégias, é uma atividade desafiadora para seus gestores. É, pois de suma importância conhecer como estas situações estão sendo encaradas, detectando seus problemas e soluções atuais, pode-se entender e equacionar as novas situações.

A tecnologia, entretanto, não constitui o único fator a ser considerado para que o uso da informática venha a produzir os resultados desejados, nas instituições públicas, o gestor de tecnologia ainda tem que superar outros desafios: falta de uma política de investimentos apropriados, ações de curto prazo, investimentos feitos com interesses eleitorais, aspectos culturais além de resistência a mudanças.

A relação entre estrutura organizacional e tecnologia tem sido alvo de grande atenção, uma vez que as recentes inovações trazem mudanças radicais nas organizações. O setor público, em especial os municípios, tem gerado constantes desafios aos administradores envolvendo questões econômicas, sociais, ambientais, culturais, políticas e de planejamento.

Essas dificuldades dizem respeito principalmente à gestão dos recursos financeiros e as discussões das temáticas legais, ou seja, obediência a Constituição Federal (CF), Lei de Responsabilidade Fiscal (LRF), Lei da Transparência Pública e outras exigências legais, somam-se a estes fatores a pressão dos munícipes para que a administração dos órgãos públicos seja cada vez mais transparente.

É importante salientar que desde o principio, a modernização do setor público brasileiro foi um passo imprescindível a ser dado, porém, para que isso ocorresse foi necessário transpor importantes barreiras, as quais tem sido o motivo pelo qual, por muitos anos, vários entes públicos municipais foram impedidos de se desenvolver em prol do cidadão, que é o grande beneficiário.

São muitas as prefeituras que necessitam de plataformas tecnológicas sob medida para suas necessidades e expectativas, aproximando-as dos cidadãos, auxiliando no crescimento das economias locais e reduzindo o custo e o tempo envolvidos nos processos.

Nesse contexto, a expressão "infraestrutura" tão difundida atualmente torna-se uma ferramenta fundamental para o desenvolvimento da Tecnologia da Informação (TI) nas gestões dos governos municipais, que, optando pela inovação, poderão oferecer melhor 
atendimento à população, além de desenvolver e ampliar o roll de serviços prestados aos munícipes.

Sobretudo, é de suma importância salientar que os avanços da TI nos entes públicos têm trazido a tona uma maior eficiência e transparência no que tange as receitas municipais. Com a utilização da TI enfraqueceu e até mesmo extinguiu em alguns casos nichos de corrupção. Permitindo também acompanhar o andamento de projetos, contratos de serviços terceirizados, verificar as informações sobre receitas e despesas, dados dos funcionários, tais como quantidade, salários, cargos.

\section{Tecnologias de Informação no Setor Público}

Hoje, a TI participa do cotidiano das organizações sejam estas privadas ou públicas, vezes como uma arma eficiente de gestão da informação e de apoio às decisões de seus gestores, vezes como uma ferramenta que afeta interesses, valores e rotinas há muito tempo centralizado em pessoas. A rapidez com que a informação e o conhecimento são criados e circulam sem fronteiras, potencializa a importância do capital intelectual.

Já no setor público brasileiro, constata-se atualmente a necessidade em transpor, primeiramente, algumas barreiras que o impedem de crescer. Por isso, infra-estrutura e apoio são essenciais para o desenvolvimento da TI nas gestões dos governos municipais, que, optando pela inovação, poderão oferecer melhor atendimento à população, além de desenvolver e ampliar os serviços. As prefeituras necessitam de plataformas tecnológicas sob medida para suas necessidades e expectativas, aproximando-as dos cidadãos, auxiliando no crescimento das economias locais e reduzindo o custo e o tempo envolvidos nos processos.

Nesse contexto, atinge-se um momento crucial em que essas mudanças devem ter início imediato, e esse começo precisa ocorrer internamente nas prefeituras através de seus funcionários sendo encorajados a aprender e a serem treinados para utilização das plataformas tecnológicas, o que possibilitará que o setor público adquira maior eficácia e qualidade. Devem compreender que as modificações atingem não só os processos e serviços da gestão pública, mas também seus planos de carreira e conhecimentos. Motivados, os funcionários prestam melhores serviços e participam ativamente da modernização e desburocratização do serviço público.

No setor público, a TI auxiliará no desenvolvimento dos municípios e na melhoria dos serviços prestados à população, que ganhará um governo mais transparente, presente e que interaja de forma mais direta com as expectativas dos cidadãos. 
Nessa conjunção, verifica-se a necessidade de um estudo com enfoque no setor tributário municipal, principalmente no que tange a arrecadação do Imposto sobre Serviço de Qualquer Natureza (ISSQN), nesse cenário o investimento na modernização das administrações tributárias municipais é um caminho para que não apenas sejam aumentadas a receita fiscal e a capacidade de auto financiamento dessa esfera, como também para se melhorar a qualidade do sistema tributário municipal.

O aumento dessa importante fonte de arrecadação tributária municipal permitirá que seus gestores tenham melhores condições para atender à crescente demanda da população por serviços de melhor qualidade e com maior abrangência social, que são carências evidentes na maioria dos municípios brasileiros.

Nesse contexto, o referido artigo tem como objetivo:

- Analisar como ocorre a implantação do Sistema da Nota Fiscal Eletrônica de Serviços, elencando as melhorias e benefícios que o sistema proporcionará para a Administração pública.

- Otimizar a atuação das administrações tributárias municipais através da adoção de solução tecnológica que propiciem o aperfeiçoamento dos procedimentos fiscais.

- Aprimorar a qualidade das informações obtidas.

- Comparar as soluções de sistemas de NFe-S disponíveis via software proprietário ou software público.

- Examinar as principais dificuldades das administrações públicas na contratação e utilização das novas tecnologias de informação, enfatizando o sistema da Nota Fiscal Eletrônica de Serviços.

\section{Software de ISS eletrônico}

Através desse sistema, as empresas prestadoras de serviços, passam a ser obrigadas a fazer escrituração eletrônica, conforme as regras e procedimentos da legislação tributária de cada município e a lei complementar $n^{\circ}$ 116/2003. Conforme a escrituração é feita, o próprio programa efetua o controle das informações digitadas, orientando o contribuinte e impedindoo de efetuar operações incorretas ou fora dos padrões estabelecidos pela legislação municipal e federal, além de efetuar o cruzamento de dados entre prestadores e tomadores de serviços, apontando para a fiscalização qualquer indício de sonegação físcal.

Com esse sistema, as prefeituras passam também a ter o conhecimento de todos os aspectos da economia de serviços do Município, desde os serviços gerados e que são 
consumidos no próprio ou em outros municípios até as empresas de fora que vem prestar serviços na cidade, indicando ainda em que local está sendo recolhido o imposto. Assim as prefeituras poderão conhecer melhor suas economias e desenvolverem planos de incremento ou incentivo a setores, com o objetivo de melhorar e economia, aumentando a base de contribuintes e conseqüentemente diminuindo alíquotas.

\section{Nota fiscal eletrônica de serviços (NFS-e)}

Frisa-se, que foi através da promulgação da Constituição Federal de 1988 no inciso XXII do art. 37 uma novidade com relação ao funcionamento dos fiscos em geral. O qual abordou-se que as informações tributárias devem tornar-se integradas entre as administrações dos Municípios, dos Estados, do Distrito Federal e da União.

Alicerçado nesta previsão e devidamente publicado na Emenda Constitucional $n^{\circ} 42$, em 19 de dezembro de 2003, as administrações tributárias passaram a realizar encontros nacionais, objetivando cumprirem este princípio legal e deliberarem as formas desta integração.

No III Encontro Nacional dos Administradores Tributários (ENAT), realizado em Fortaleza no ano de 2006, foi assinado o protocolo de cooperação ENAT nº ${ }^{\circ}$ 01/2006. Com as regras previstas neste documento foi iniciado todo o processo de criação das notas fiscais eletrônicas no Brasil. Com base nestas regras, também foi iniciado o processo de criação da Nota Fiscal de Serviços Eletrônica - (NFS-e).

Todo o processo de implantação da NFS-e foi desenvolvido através da Associação Brasileira das Secretarias de Finanças das Capitais (ABRASF) e contou com a participação efetiva dos representantes de oito capitais responsáveis por este projeto.

Não obstante ao registro da transferência de propriedade de um produto ou serviço durante muito tempo deu-se por meio de documentos fiscais no formato em papel, com o advento de novas tecnologias de informação e a facilitação de acesso à internet, se tornou plausível a implantação de sistema informatizado do registro desses documentos fiscais, mais especificamente a NFS-e. O objetivo deste estudo é verificar se o referido sistema proporciona melhorias no que se refere à redução da burocracia, a maior facilidade, maior comodidade, economia e segurança e finalmente incremento na arrecadação do ISS municipal.

Nesse contexto, salienta-se o conceito da NFS-e "é um documento de existência exclusivamente digital, gerado e armazenado eletronicamente pela prefeitura ou por outra 
entidade conveniada, para documentar as operações de prestação de serviços". (www.receita.fazenda.gov.br). A geração da Nota Eletrônica (NE) será feita, automaticamente, por meio de serviços informatizados, disponibilizados aos prestadores de serviços. Para que sua geração seja efetuada, dados que a compõem serão informados, analisados, processados, validados e, se corretos, gerarão o documento.

A responsabilidade pelo cumprimento da obrigação acessória de emissão da NFS-e se fará pelo correto fornecimento dos dados à secretaria fazendária municipal, para a geração da mesma, nesse processo o prestador de serviço, devera acessar o sitio do município, onde oportunamente estará o link do referido sistema.

\section{Principais benefícios na utilização da NFS-e}

Cabe abordar, entretanto, alguns aspectos que fazem uma grande diferença para todos nós. Passaremos a ser, de fato, uma sociedade mais justa e de responsabilidade cidadã, importante dizer que desde a implantação e utilização do referido sistema por parte dos entes municipais já antevia-se uma série de benefícios que seriam alcançados com as medidas estabelecidas nessa inovação. Abaixo elenca-se alguns desses benefícios:

Sobretudo, Furlan (2009) em seu trabalho científico salienta: aumento de arrecadação dos impostos; maior eficiência da físcalização; sensível redução da burocracia; maior transparência; estímulo à cidadania fiscal (inclusive mediante a devolução parcial de tributos, por exemplo o munícipe poderá ter determinado credito), quando esse informa o $\mathrm{CPF}$ ou CNPJ na emissão da NFS-e; sensível redução de papel a ser utilizado na NFS-e (são eletrônicas, sem necessidade de impressão) e de todos os demais registros, pastas, caixas etc. utilizados na manutenção e guarda desses documentos. Isso proporcionará um benefício a todos, por conta da preservação da natureza.

Para a sociedade em geral, especialmente aos profissionais:

- Surgimento de empresas de tecnologia e consultorias especializadas, com oportunidade de formação e consolidação técnica de várias pessoas;

- Ainda que possa parecer pequena, haverá uma redução do chamado custo Brasil, que impacta todos os preços;

- O incentivo ao uso de novas tecnologias por parte de uma grande parte da população que estava alijada dessa condição (inclusão digital e tecnológica).

Principais desafios que deverão ser transpostos: grande demanda e baixa disponibilidade de profissionais e empresas qualificadas; baixo número de gestores públicos 
com boa experiência no tema "tecnologia"; mudança cultural associada aos projetos; risco de continuidade (possibilidade de projeto estar vinculado a "governante" em vez de ser um programa de governo); uso objetivo das informações pela administração tributária dos entes (município, estado, união).

A tendência é pela modernização tributária, cujo sucesso pleno depende também da forma de comunicação, do planejamento e do apoio de uma empresa especializada e com experiência comprovada no desenvolvimento e implantação do referido sistema nos entes municipais, que atendam às necessidades inerentes a todo o processo.

\section{Diferenças entre software público e proprietário}

Conforme texto publicado por Rezende (2006) no "Observatório da Imprensa": No software proprietário, o programador abdica da liberdade de controlar sua obra, em troca de salário e compromisso de sigilo. O distribuidor, fantasiado de 'fabricante', torna-se proprietário de tudo. Desde o código fonte, tido como segredo de negócio, até as cópias executáveis, licenciadas ao usuário sob custódia e regime draconiano. Enquanto no software livre o programador abdica de um dos canais de receita pelo seu trabalho, em troca da preservação do controle dos termos de uso da sua obra. Em contrapartida, se a obra tiver qualidades, agregará eficiência aos empreendimentos em torno dela. Seu valor semiológico, conversível em receita com serviços, será proporcional à magnitude do esforço colaborativo onde se insere. $\mathrm{O}$ código fonte é livre sob licença que preserva esta liberdade, enquanto a cópia executável é tida como propriedade do usuário. [...] Só tem a perder com ele (Software Livre) quem consegue galgar posições monopolistas no modelo proprietário. O problema é que a ganância faz muitos acreditarem que serão os eleitos pelo deus mercado, enquanto seguem correndo atrás da cenoura amarrada na ponta da vara que pende das suas carroças digitais, não se importando com os efeitos colaterais de se tratar conhecimento como bem escasso, ao considerarem software como mercadoria.

Nesse contexto, vale uma análise o que realmente é melhor para uma administração pública a utilização de um modelo usual onde o órgão público fica atrelado a um contrato de licença de uso na utilização de software proprietário, ou migrar para um "novo" modelo na utilização do sistema via software público, assim ao invés de ficar pagando pelo aluguel do software passa a ser donos dos referidos softwares.

Ainda, conforme, Spagnolo (2005) software proprietário: [...] distribuído sem a liberação de seu código fonte. Assim normalmente comercializado sob termos de uma licença 
de uso. Essa licença define uma série de termos os quais o usuário deve respeitar para estar habilitado a usar o software. Porque o código fonte não está acessível, são tecnicamente impossível modificar o software. Exemplos: Microsoft Windows e Winzip.

Nesse cenário, de acordo, Terceiro (2011) cita algumas das razões para se utilizar Software Livre: poder utilizar o software para qualquer finalidade; ter acesso ao código fonte e poder modificá-lo, sem quaisquer restrições; poder copiá-lo e executá-lo em quantas máquinas desejar; poder distribuí-lo, sem violar, é claro, essas liberdades a que todos têm direito; ter o seu computador equipado com software de qualidade a um custo baixo ou nulo; não ficar preso às restrições impostas pelas licenças de softwares proprietários; não ficar dependente de novas versões com preços abusivos que eventualmente apresentam incompatibilidades com versões antigas; não ficar dependente de um fornecedor; ficar livre da pirataria; incentivar o desenvolvimento de tecnologia local; interagir e compartilhar soluções com sua comunidade, seja física ou virtual; lutar contra o monopólio de grandes corporações que tentam se apropriar do conhecimento intelectual coletivo para benefício próprio.

\section{Custo total de uso e propriedade}

Conforme editorial, Instituto Ecos (2011) verifica-se que: “o custo total de propriedade - TCO (total cost of ownership) é um sistema de cálculo destinado a assistir os consumidores na avaliação dos custos, assim como os benefícios relacionados à compra de componentes para a gestão da TI."

Nesse contexto, Padoveze (2007, p. 325) da o seguinte enfoque: A ideia é mensurar continuadamente quanto é gasto com a estrutura de tecnologia e sistemas de informações. Em outras palavras, quanto custa para a empresa manter funcionando sua estrutura de TI. Não é tarefa fácil. Alem de a maneira das empresas possuírem estruturas descentralizadas, não basta somar os gastos com hardware, redes, softwares e com pessoal do departamento de informática. Também os custos ocultos (hidden costs) devem ser calculados e incorporados no modelo de mensuração.

Num órgão público, também vai ocorrer essa mensuração dos custos que estão sendo empregados em determinada implantação de software, por isso o TCO torna-se igualmente peça fundamental no setor público.

Conforme publicado, no Instituto Ecos (2011) o qual trouxe a tona o objetivo principal da TCO é a “[...] obtenção de um número que contemple todos os custos envolvidos ao longo do ciclo de vida de uma solução de TI, deve incluir": custos do hardware e das licenças de 
software; amortização; manutenção; up-grades; suporte técnico; tempo ocioso por falhas; segurança (vírus/worms/etc., denial of service, back-up, reparações, etc.); treinamento; administração; tempo de operação (tempo comparativo dedicado à execução de um tarefa).

Além disso, Padoveze (2007, p. 326), complementa contexto acima afirmando que: O objetivo do TCO é avaliar se os valores investidos em TI vão-se pagar e em quanto tempo. É o calculo continuo do Retorno do Investimento (ROI), feito não apenas para projetos específicos, mas também para o funcionamento do departamento de informática.

De forma prática, Mitre (2001, p.3) afirma que estes custos podem ser categorizados da seguinte forma: Custos diretos (aqueles que podem ser quantificáveis) hardware (aquisições e upgrades) e software (aquisições, upgrades, licenças) - 25\%; suporte (remoto, treinamento, deslocamento, manuais e livros) - 16\%; manutenção - $21 \%$; desenvolvimento (aplicações e conteúdo) - 5\%; comunicação (infra-estrutura e taxas) - 4\%. Custos indiretos (não quantificáveis) custo de usuário final (suporte casual e auto-aprendizado) - 21\%; downtime (perda de produtividade devido a paradas) - $7 \%$.

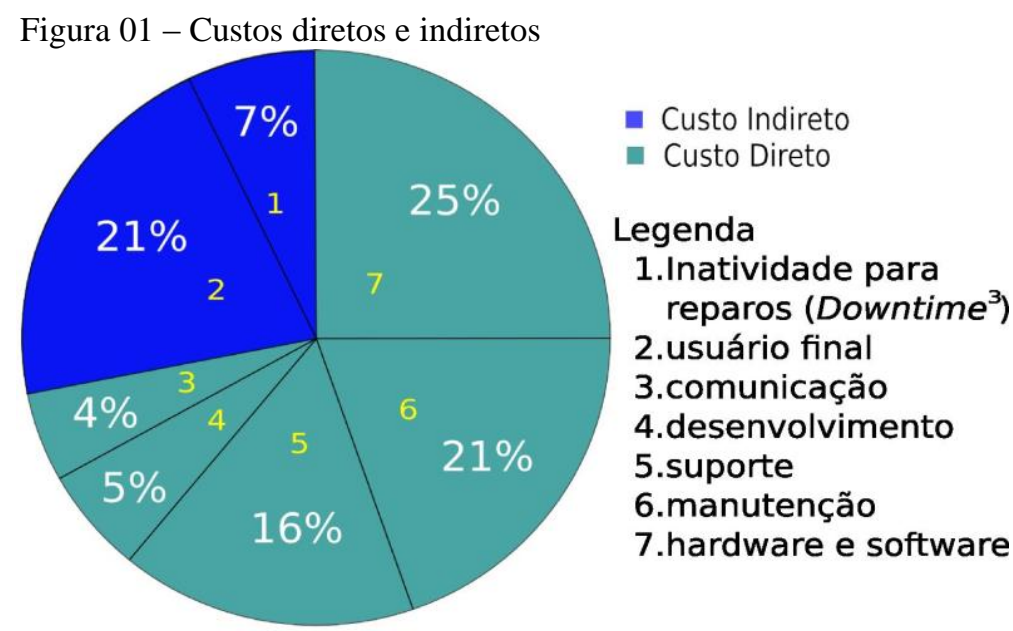

Fonte: Revista TECCEN (2010, p.4). 
Por fim, conforme texto, já mensurado de forma ampla anteriormente dá um enfoque geral dos benefícios na adoção de uma tecnologia onde a metodologia mais abrangente e realista que a simples utilização do TCO. Esta visão contempla aspectos como custos associados, flexibilidade e riscos de implantação. Estes elementos, muitas vezes não quantificáveis, adquirem importância crescente ao longo do ciclo de vida de uma tecnologia. Assim, podemos definir esses componentes da seguinte forma: custos: que se correspondem àqueles elementos contemplados pelo TCO; benefícios: aumento na produtividade e penetração de mercado; flexibilidade: viabilização de novos negócios e/ou mercados; riscos: problemas com fornecedores e componentes inadequados.

\section{Análise comparativa: software proprietário vs. software público ou livre}

Nesse ponto, salienta-se que até agora, pode-se verificar alguns pontos cruciais que se revelaram ser importantes tanto para os software proprietários como para os software público ou livre, nessa abordagem avalia-se a seguir um conjunto de argumentações lógicas para melhor analisar as vantagens e desvantagens na utilização de soluções desenvolvidas a partir de software proprietário e de software público ou livre.

Para isso, corrobora o editorial do Instituto Ecos (2011), vastamente examinado nesse capitulo, para tal traz algumas diferenças entre os respectivos softwares que é importante serem mencionados:

Software proprietário: os clientes têm que comprar perpetuamente novas licenças de software, manutenções e suporte; baseiam seu modelo comercial na venda de licenças, o que leva a que no lançamento de novas versões, muitas vezes dê-se maior ênfase nos aspectos cosméticos que na estabilidade e segurança da solução; é desenvolvido centralmente e a partir de projetos planejados a-priori, o que dá maior consistência à solução. Em se tratando de aplicações com módulos e funcionalidades muito heterogêneas, a centralização do planejamento e desenvolvimento de software é importante; o desenvolvimento de aplicativos customizados é realizado com a utilização de linguagens proprietárias, o que acresce custos de aquisição de licenças e treinamento complementar; a empresa garante e responsabiliza-se legalmente pelo resultado da utilização do software, sendo possível para o cliente a utilização de mecanismos judiciais para assegurar seus direitos de consumidor.

Software público ou livre: com o Software de código aberto (incluído o software livre) não há custo repetitivo para licenciar o uso do software. Compra-se só uma vez. Instalam-se quantas cópias seja necessárias, com o software de código aberto isto não é necessário, porém o suporte é limitado aos fórum de usuários e outras alternativas similares. $\mathrm{O}$ lançamento de novas versões e manutenções depende, basicamente, da dinâmica do desenvolvimento comunitário. Se existir uma empresa ou instituição responsável pela implementação do software de código aberto, a incerteza da falta de um cronograma de lançamentos pode ser contornada através de contratos de suporte e manutenção que diminua o downtime do desenvolvimento comunitário; o software de código aberto, que considera o software como um serviço, as novas versões buscam melhorias técnicas reais, já que não existe o incentivo comercial da venda de licenças; as alternativas de software de código aberto para gestão espacial vem sendo desenvolvidas a partir de projetos díspares, com linguagens e modelos totalmente diferentes, o que diminui o desempenho e a eficiência na sua utilização, aumentando os custos de implantação, customização e treinamento. Por isso, a decisão em favor do software de código aberto deve ser acompanhada de uma estrutura de desenvolvimento, manutenção e suporte, complementar às atividades da comunidade, no caso do software de código aberto, utilizam-se linguagens abertas, que não requerem 
licenciamento; deve-se buscar utilizar software independente de plataforma, pelo menos para a implementação de clientes, o que facilita a estruturação de soluções flexíveis e fáceis de migrar e gerenciar; o software de código aberto é fornecido sem qualquer garantia, não existindo qualquer responsabilidade por parte do desenvolvedor sobre as consequências na utilização do software. No caso da implementação do software com a participação de uma empresa ou instituição responsável, este problema pode ser contornado.

\section{Comparativo de custos entre o software público $\mathrm{x}$ software proprietário}

Na tabela 1, será apresentado os custos para a contratação do Sistema e-Nota Software Público contempla período de contratação de 01 (um) ano, num determinado município gaúcho.

Tabela 01 - Custo implantação da NFe-S via software público

\begin{tabular}{llllll}
\hline Fases & Ações & Horas & $\mathrm{N}^{\circ}$. Prof & $\begin{array}{l}\text { Custo hora } \\
\text { Prof }\end{array}$ & Custo \\
\hline Fase 1 & Integração & 180 & 2 & $\mathrm{R} \$ 115,00$ & $\mathrm{R} \$ 20.700,00$ \\
Fase 2 & Implantação & 180 & 2 & $\mathrm{R} \$ 95,00$ & $\mathrm{R} \$ 17.100,00$ \\
Fase 3 & Treinamento & 60 & 1 & $\mathrm{R} \$ 65,00$ & $\mathrm{R} \$ 3.900,00$ \\
Fase 4 & Suporte e Manutenção & 400 & 2 & $\mathrm{R} \$ 40,00$ & $\mathrm{R} \$ 16.000,00$ \\
\hline Total & & & $\mathrm{R} \$ 315,00$ & $\mathrm{R} \$ 57.700,00$ \\
\hline
\end{tabular}

É importante frisar que numa opção de contratação do sistema via software público, o ente público, tem os custos de: integração, implantação, treinamento, suporte e manutenção, porém, isso apenas no primeiro ano, a partir do segundo ano há uma diminuição de $30 \%$ do valor referente pago na implantação.

A tabela 2, a seguir referente a contratação Sistema Nota fiscal eletrônica de serviços - Software Proprietário, contempla período de contratação de 01 (um) ano.

Tabela 02 - Custo implantação da NFe-S via software proprietário

\begin{tabular}{clcccc}
\hline Fases & \multicolumn{1}{c}{ Ações } & Horas & $\mathbf{N}^{\mathbf{0}}$ Prof & Custo hora P/ Prof & Custo \\
\hline Fase 1 & Integração & 180 & 2 & $\mathrm{R} \$ 220,00$ & $\mathrm{R} \$ 39.600,00$ \\
Fase 2 & Implantação & 180 & 2 & $\mathrm{R} \$ 200,00$ & $\mathrm{R} \$ 36.000,00$ \\
Fase 3 & Treinamento & 60 & 1 & $\mathrm{R} \$ 100,00$ & $\mathrm{R} \$ 6.000,00$ \\
Fase 4 & Suporte e Manutenção & 400 & 2 & $\mathrm{R} \$ 80,00$ & $\mathrm{R} \$ 32.000,00$ \\
\hline \multicolumn{2}{c}{ Total } & & & $\mathbf{R} \$ \mathbf{6 0 0 , 0 0}$ & $\mathbf{R} \$ \mathbf{1 1 3 . 6 0 0 , 0 0}$ \\
\hline
\end{tabular}

A tabela 03 apresentara a diferença monetária na utilização do Sistema da Nota Fiscal Eletrônica de Serviços em 04 anos de utilização, ou seja, período de uma administração.

Tabela 03 - Evolução dos custos em 04 anos

\begin{tabular}{lll}
\hline Período & Software público & Software proprietário \\
\hline Ano 01 & $\mathrm{R} \$ 57.700,00$ & $\mathrm{R} \$ 113.600,00$ \\
Ano 02 & $\mathrm{R} \$ 40.390,00$ & $\mathrm{R} \$ 124.960,00$ \\
Ano 03 & $\mathrm{R} \$ 44.429,00$ & $\mathrm{R} \$ 137.456,00$ \\
Ano 04 & $\mathrm{R} \$ 48.872,00$ & $\mathrm{R} \$ 151.201,00$ \\
\hline Total & $\mathrm{R} \$ 191.391,00$ & $\mathrm{R} \$ 527.217,00$ \\
\hline
\end{tabular}

- Correção após ano 02 ocorrerá a partir da média INPC na tabela acima com uma estimativa de $10 \%$ a.a. 
Gráfico 01 - Comparativo dos custos na utilização do sistema da NF-eS

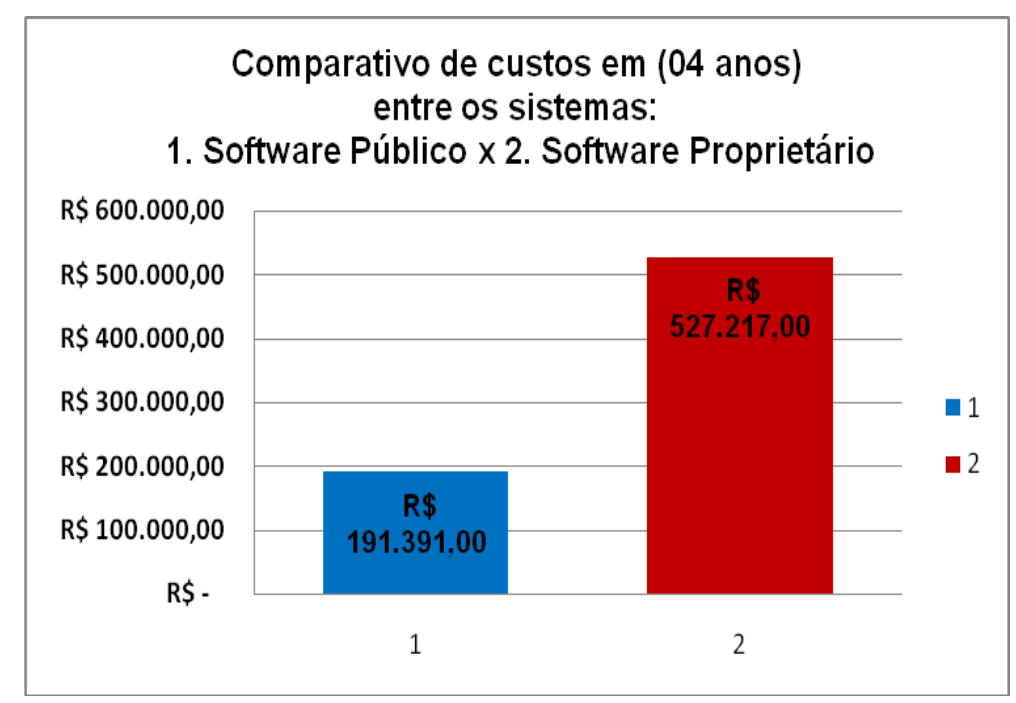

Fonte: Autoria própria, 2011

Numa avaliação econômica e financeira em 04 anos de utilização de sistema constatase uma economia de $\mathrm{R} \$ 335.826,00$ aos cofres públicos do município. Em percentual isso significa uma diferença de $275 \%$ em prol pela escolha do sistema via software público.

\section{Considerações Finais}

Diante da necessidade de haver um incremento da arrecadação tributária municipal o referido artigo vivenciou vastamente essa temática, conforme os objetivos propostos iniciais, "o custo total de uso e propriedade no processo de aquisição de sistemas de informação no âmbito da gestão publica municipal", portanto, conclui-se que a finalidade sugerida nesse artigo foi alcançada com êxito.

Nesse pressuposto, viu-se que os municípios brasileiros têm encontrado muitas dificuldades de controle fiscal e gerencial na arrecadação de seus tributos municipais. Esse artigo tem o intuito de alertar para a importância que se tem na arrecadação desse tributo, assim como trazer a tona uma discussão sobre as políticas adotadas atualmente pelas administrações públicas, no que tange a arrecadação tributária do ISSQN.

$\mathrm{Na}$ busca de uma forma para atenuar a sonegação e evasão fiscal decorrentes no setor, tem-se procurado práticas e avanços na qualidade dos controles administrativos, pelo fortalecimento das regras e processos neles contidos, e principalmente através de tecnologia disponível atualmente no mercado em evidencia a "internet" na qual muitos municípios já tem investido com êxito. Dessa forma, todos esses procedimentos, são disponibilizados aos contribuintes pela internet, esses inserem as informações de interesse do Fisco, a partir dai, essas são captadas e processadas de acordo com a necessidade do setor.

Nesse pressuposto, ficou evidente nesse artigo que há uma perene necessidade dos municípios brasileiros, em implantar urgente ferramentas modernas de TI, que visem principalmente auxiliar setores responsáveis pelas áreas: arrecadação, segurança, saúde, educação, etc.

No decorrer desse artigo cientifico, observou-se através do referencial teórico que os benefícios advindos da Tecnologia de Informação são inquestionáveis, pois os controles e concomitantes, além de garantirem uma maior qualidade de serviços prestados ao cidadão com a possibilidade da utilização de sistemas de TI com o menor custo, asseguram a correta 
aplicação dos recursos, prevenindo a ineficiência na administração pública, contribuindo para o cumprimento da missão do ente público.

Ao longo daquilo que foi amplamente abordado nesse artigo, verificou-se que a Tecnologia da Informação, no setor tributário, evidenciando o sistema da nota fiscal eletrônica de serviço confirmou-se, como um aliado imprescindível da administração tributária, além da modernidade que o sistema propicia também é uma ferramenta eficaz no combate a sonegação e evasão fiscal de ISS no município. Com a utilização dessa tecnologia o sistema vai rodar numa plataforma de comunicação web, trazendo modernidade ao município, possibilitando o monitoramento de funções internas e digitalização de processos, tornando mais ágeis funções que antes eram feitas de forma manual. Dessa forma, acaba por combater diretamente alguns males recorrentes nos processos burocratizados dos entes públicos.

O referido artigo constatou também, que o sistema disponibilizado para a emissão de notas eletrônicas adotado atualmente por inúmeras prefeituras em todo país chegou para revolucionar o mercado brasileiro. As prefeituras que estão investindo nessa tecnologia conseguem dados de registros das operações como, por exemplo: prestadores que mais tem contribuído com ISSQN no município, relação de inadimplentes, setores de serviços que mais tem fomentado a economia no município, tomadores que mais se utilizam de serviços no município e ainda uma gama de relatórios gerenciais que outrora não se obtinha todos esses dados em tempo real.

Sobretudo verificou-se que a $\mathrm{NFe}-\mathrm{S}$ sem dúvida alguma tem se tornado um dos principais aliados no controle fiscal e gerencial, principalmente no que tange a tomada de decisão por parte de seus administradores em políticas públicas que vislumbrem melhorias ao cidadão.

Logicamente, que num pressuposto inicial, constatou-se que a melhor forma de utilização do sistema de nota fiscal eletrônica de serviços por parte de uma prefeitura é através da modalidade "software público".

Conforme, o que foi mencionado nesse artigo, o qual, utilizou-se a técnica de se calcular o custo total de propriedade - TCO (total cost of ownership) onde traçou-se um comparativo na relação custo x beneficio por parte de uma determinada prefeitura, nesse momento foi possível mensurar o custo de oportunidade por parte do município em utilizar o sistema da NFe-S via software proprietário ou software público.

Nesse contexto, no Encontro Nacional de Tecnologia da Informação realizado no ano de 2011 em Brasília/DF, a então Ministra do Planejamento, Orçamento e Gestão, Miriam Belchior, defendeu a utilização do portal do software público pelas cidades brasileiras. De acordo com a Ministra, o ambiente virtual possibilita o acesso universal e transparente a um conjunto de soluções informatizadas direcionadas para a gestão pública municipal. "Centenas de prefeituras são beneficiadas pelas soluções do portal, que possibilitam essa melhoria de gestão do sistema escolar, tributário, financeiro, do atendimento ao cidadão e de automatização de funções administrativas de patrimônio, frota, compras e estoque", (BELCHIOR, 2011). A Ministra salienta ainda "permite uma independência por parte dos municípios que têm dificuldade em acessar, por causa dos custos proibitivos, uma série de sistemas administrativos para melhorar a sua gestão pública" (BELCHIOR, 2011).

Nesse mesmo evento, o então Ministro das cidades, Mário Negromonte, defende veementemente que a tecnologia da informação permite socializar metodologias de comunicação de forma segura, tornando-os assim mais eficaz e aumentando a sua efetividade. Por isso, corrobora dizendo: "[...] os gestores municipais não podem deixar de utilizar as ferramentas de TI. A comunicação está cada vez mais informatizada e os gestores não podem prescindir de dar mais transparência à administração pública”. (NEGROMONTE, 2011). 
Dessa forma, vislumbra-se que as políticas adotadas atualmente pelo Governo Federal, são de incentivo incondicional a esse novo modelo de disposição de softwares que exprimi na mobilização para a melhoria dos serviços ao cidadãos por meio da ampliação da utilização de ferramentas de TI pelos municípios brasileiros.

Por fim, conforme amplamente explanado nesse artigo sugere-se que as administrações públicas antes mesmo de efetivar contratações de sistemas de TI, procurem conhecer a gama de softwares disponíveis através do Software Público Brasileiro que encontram-se a disposição para imediata utilização dos entes públicos em todo país

\section{Bibliografia Consultada}

ALTER, S. Information Systems: a management perspective. 2.ed. [s.1.]: Menlo Park CA: Benjamin e Cummings, 1996.

ANDRADE, Maria Margarida de. Como preparar trabalhos para cursos de pós-graduação: noções práticas. 5.ed. São Paulo: Atlas, 2002.

BEUREN, Ilse Maria. Como elaborar trabalhos monográficos em contabilidade: teoria e prática. 2.ed. São Paulo: Atlas, 2004.

BIO, S. R. Sistemas de Informação: Um enfoque Gerencial. São Paulo: Atlas, 1988.

BOVO, J. M., FONSECA, S. A. \& RIBOLDY, R. A tecnologia da informação no processo de modernização promovido pelo PMAT-BNDES no município de São José do Rio Preto. II ENAPG 2006, São Paulo, Novembro, Anais do Evento.

BRASIL. Constituição da República Federativa do Brasil de 1988. Disponível em: <http://www.planalto.gov.br/ccivil_03/Constituicao/Constituicao.htm>. Acesso em: 22 set. 2011.

BRASIL. Lei 4.320, de 17.03.1964. Estatui normas gerais de direito financeiro para elaboração e controle dos orçamentos e balanços da União, dos Estados, dos Municípios e do Distrito Federal. Disponível em:

<http://www.planalto.gov.br/ccivil_03/Leis/L4320.htm>. Acesso em: 22 set. 2011.

BRODBECK, A.F.; HOPPEN, N. Alinhamento estratégico entre os planos de negócio e de tecnologia de informação: um modelo operacional para a implementação. In: XXVIENANPAD, 2002, Salvador, Anais em CD Rom.

CERVO, Amado Luiz; BERVIAN, Pedro Alcino; SILVA, Roberto da. Metodologia científica. 6.ed. São Paulo: Prentice-Hall, 2007, 162 p.

CUNHA, M. A., MARQUES, E. V. \& MEIRELLES, F. S. Modelos de gestão de tecnologia de informação no setor público brasileiro. I ENAPG 2004, Salvador, Setembro, Anais do Evento.

DAVENPORT, T. H. Reengenharia de Processos, como inovar na empresa através da tecnologia da informação. 6.ed. São Paulo: Campus, 1996. 
FLEURY, Maria Tereza Leme; FISCHER, Rosa Maria. Cultura e poder nas organizações. Rio de Janeiro: Atlas, 1996.

FREITAS, H., LESCA, H. Competitividade empresarial na era da informação. Revistada administração da USP, São Paulo, Jul/Set. 1992.

FUNDASP.

$<$ http://www.fundap.sp.gov.br/públicacoes/TextosTecnicos/textec1.htm> . Acesso em 20 set de 2011.

GIL, A. C. Métodos e técnicas de pesquisa social. 5.ed. São Paulo: Atlas,1999.

GOLDENBERG, Mirian. A arte de pesquisar: como fazer pesquisa qualitativa em ciências sociais. 5.ed. Rio de Janeiro: Record, 2001.

GOLLO, Marcelo Ribeiro. Aspectos da gestão tributária no mnicípio. Disponível em $<$ http://jus.com.br/revista/texto/18947/aspectos-da-gestao-tributaria-no-municipio > Acesso em 30 ago. 2011.

GUAGLIARDI, J. A.; REZENDE, D. A. Estratégias, sistemas de informação, tecnologia da informação, planos e planejamentos municipais: alinhamento e contribuições em 2 prefeituras de capitais brasileiras. Balneário Camboriú: SLADE-Encontro Luso-Brasileiro Estratégia, 2006.

HELBERT, Carvalho Tiago. Benefícios e dificuldades na implantação de sistemas ERP. Disponível em: 〈http://www.linhadecodigo.com.br/Artigo.aspx?id=2514> Acesso em: 02 nov. 2011.

INSTITUTO ECOS. Custo Total de Propriedade - TCO. Análise comparativa. Disponível em: <http://www.institutoecos.org.br/br/software/license/tco.htm> Acesso em 03 nov. 2011.

KLIKSBERG, Bernardo. Como transformar o Estado, para além dos mitos e dogmas. Brasília: ENAP, 1992.

LAUDON, K. C.; LAUDON, J. P. Sistemas de Informação. São Paulo. LTC, 2000.

LOBLER, M., MARQUES, C. S.; VISENTINI, M. S. Dimensionamento da tecnologia da informação no setor público: Em Estudo Exploratório nos Municípios do Estado do RS. II ENAPG/2006, São Paulo, Novembro, Anais do Evento.

MACHADO Jr., José Teixeira; REIS, Heraldo da Costa. A Lei 4.320 comentada. 30.ed. Rio de Janeiro: IBAM.

MATTAR, J. A. N. Metodologia cientifica na era da informática. São Paulo: Saraiva, 2005.

MEIRELLES, Hely Lopes. Direito municipal brasileiro. São Paulo: Malheiros, 1993. 
MELlO, Curso de direito administrativo: Revista e Atualizada até a Emenda Constitucional 57. 26.ed. São Paulo: Malheiros, 2009.

NOGUEIRA, Roberto Wagner Lima. Fundamentos do dever tributário. Belo Horizonte: Del Rey, 2003.

PIETRO, Direito administrativo. 16.ed. São Paulo: Atlas, 2003.

PISCITELLI, TIMBÓ; ROSA, Contabilidade pública: Uma abordagem da administração pública. 9.ed. São Paulo: 2006.

POHLMANN, Marcelo Coletto; IUDÍCIBUS, Sérgio de. Tributação e política tributária. Uma abordagem interdisciplinar. São Paulo: Atlas, 2006.

POZZEBON, Cristiane; SILVEIRA, Samarone Guedes. Manual para apresentação de trabalhos acadêmicos do Centro Universitário La Salle (recurso eletrônico) 3.ed. 2011. Disponível em: 〈http://academicos.unilasalle.edu/portal.php〉.

PREFEITURA MUNICIPAL FELIZ. Secretaria Municipal da Fazenda. 2011. Disponível em: <http://www.feliz.rs.gov.br>. Acesso em: 29 out. 2011.

PREFEITURA MUNICIPAL SÃO PAULO. Secretaria Municipal da Fazenda. 2011. Disponível em: <http://www.receita.fazenda.gov.br> Acesso em: 20 jul 2011.

REZENDE, D. A. Engenharia de software e sistemas de informação. Rio de Janeiro: Brasport, 1999.

D. A. Alinhamento da tecnologia da informação ao planejamento municipal: análise da prática de gestão de uma prefeitura. ENANPAD 2004, Curitiba, Setembro, Anais do Evento.

D. A. Planejamento estratégico municipal como proposta de desenvolvimento local e regional de um município paranaense. Curitiba. Revista FAE -Tema Desenvolvimento Regional. Jul/Dez 2006.

ROESCH, Sylvia Maria Azevedo. Projetos de estágio e de pesquisa em administração: guia para estágios, trabalhos de conclusão, dissertações e estudos de caso. 2.ed. São Paulo: Atlas, 1999, 301 p.

SAYAGUES LASO, Enrique. La Licitación pública. 4.ed. atual. por Daniel H. Martins. Montevidéu: Acali, 1978.

SALOMON, Délcio Vieira. Como fazer uma monografia. 11.ed. São Paulo: Martins Fontes, 2004.

SANNA, Eng. Murched B. Sucesso na implantação de sistemas. Disponível em: <http://sanna.com.br/sce-g-1.htm > Acesso em 03 out. 2011. 
SLOMSKI, Manual de contabilidade pública: Um enfoque na contabilidade municipal. 2.ed. São Paulo: Atlas, 2010.

SUNDFELD, Carlos Ari. Licitação e contrato administrativo. São Paulo: Malheiros, 1994.

TERCEIRO, Antônio. Cartilha de software livre. Projeto Software Live Bahia. 2.ed. Bahia: 2005.

< $\underline{\text { http://www.receita.fazenda.gov.br/> Acesso em } 30 \text { ago. } 2011 .}$

<http://www.sefaz.am.gov.br/educacaoFiscal/modulo03.doc/> Acesso em 30 ago. 2011.

<http://www.paragonti.com/PAPEL_SISTEMAS_INFORMACAO_MODERNIZACAO_GE STAO_PÚBLICA.pdf $>$ Acesso em 21 out. 2011.

<https://aicoura.wikispaces.com/Software+Livre+vs+Software+Propriet\%C3\%A1rio $>$ Acesso em: 17 out. 2011.

<http://www.softwarepublico.gov.br/news-item231> Acesso em 01 nov. 2011.

$<$ http://www.planejamento.gov.br/noticia.asp?p=not\&cod=7756\&cat=94\&sec=7> Acesso em 01 nov. 2011. 